\title{
Management of Breast Cancer in Old Age
}

\author{
BASIL A. STOLL, ${ }^{*}$ F.F.R., M.R.C.S. ; THOMAS H. ACKLAND, $†$ M.D., M.S., F.R.c.S.
}

\begin{abstract}
Cummary: In a retrospective survey of 301 women aged over 70 with breast cancer the factors affecting five-year survival are evaluated. The local disease is more advanced when the patient presents with it in old age than in younger women, possibly associated with a lesser degree of awareness or a long history of the primary tumour. It is not associated with a different average rate of tumour growth in old age, as measured by scar recurrences after surgery. Radical surgery may be followed by a high five-year survival rate in patients carefully selected on medical grounds, but in this unselected series the five-year survival rate was practically the same whether the local disease was limited or extensive at presentation and whatever the treatment given. The probability of five-year survival in a woman over 70 with breast cancer will depend mainly on her general health.
\end{abstract}

\section{Introduction}

It is not easy to demonstrate the value of curative therapy in breast cancer in old age because of the high death rate from intercurrent disease. In the management of the individual patient this inevitably leads to difficulty in deciding whether to aim at cure by radical surgery, or to attempt only palliation by local surgery, radiation therapy, or hormonal therapy. The decision may be clarified by examining the results of treatment in a large unselected series of such cases. This retrospective survey of 301 women over 70 presenting with breast cancer examines the characteristics of the disease and compares the results of radical and palliative treatment.

\section{Extent of Local Growth}

Among 1,141 patients with breast cancer who presented for treatment in the period 1952 to 1957 at the Melbourne Cancer Institute 301 were aged 70 to 95 . At least five years' follow-up was available in all cases. Classified according to the stage of the disease, $56 \%$ of these older patients were found to be technically operable-that is, in stages 1 or 2 , Manchester system (Paterson, 1948). A further $35 \%$ had advanced local disease without clinical evidence of distant metastases, while the remaining $9 \%$ presented with clinical evidence of distant spread. Comparison of this distribution with that in the younger age groups (Table I) shows that the proportion of patients with locally advanced disease, but without distant metastases, increases with increasing age $\left(x^{2}=49.5, P<0.001\right)$.

A higher proportion of advanced local disease in patients presenting in old age has also been noted by others (Kraft and Block, 1962; Philip, 1967). It most probably reflects the lesser awareness of the aged patient and also a longer history of tumour growth. Our analysis does not show a different rate of tumour growth in the older age group (see below). It is of interest that Bloom (1950) showed a higher proportion of locally advanced disease in patients with longer histories of a primary tumour, but in spite of this he found that the fiveyear survival was not necessarily affected by this factor.

\footnotetext{
* Honorary Consultant to Radiotherapy Department, St. Thomas's Hospital, London S.E.1; formerly Consultant Radiotherapist to Cancer Institute, Melbourne.

† Consultant Surgeon to Royal Melbourne Hospital, Victoria, Australia; formerly Consultant Surgeon to Cancer Institute, Melbourne.
}

\section{Rate of Tumour Growth}

To assess the rate of growth of breast cancer in the aged, the interval between mastectomy and the first objective evidence of recurrence in the scar area was assessed. (It was assumed to reflect the length of time required for the tumour to grow from microscopic size to a visible or palpable nodule of average diameter $0.5 \mathrm{~cm}$.) The detection of recurrences in the axilla or supraclavicular region, depending as it does on clinical acumen in examination and subject to differences in interpretation, is regarded as a less reliable index. The duration of history of the primary tumour, as given by the patient, is regarded as the least reliable index of rate of growth, as such estimates in the elderly are notoriously vague.

In the 205 patients in the series who developed scar recurrence the interval between mastectomy and scar recurrence was tabulated according to the age group of the patient. The percentage of recurrences within three years is not significantly different in the older age group from that in the others (Table II). Patients who had received postoperative radiation to the scar area were assessed separately, and it is notable that the mean recurrence-free period was not significantly different between the age groups, whether or not radiation was given (Table III).

There is consequently no evidence in our series that the average rate of growth of scar recurrences is slower in the older patient with breast cancer. It must be taken into account, however, that tumours with a tendency to recur in the scar may not be typical of the group, and may represent a different grade of malignancy from the others. It should also be noted that the higher proportion of early deaths from intercurrent disease in the older age group would tend to eliminate patients with late recurrence.

TABLE I.-Distribution of Cases by Stage According to Age Group in 1,141 Women with Breast Cancer

\begin{tabular}{|c|c|c|c|c|c|c|c|c|}
\hline \multicolumn{5}{|c|}{$\begin{array}{c}\text { Age } \\
\text { Group }\end{array}$} & \multirow{2}{*}{$\begin{array}{c}\text { Stages } \\
1 \text { and } 2 \\
81(74 \%) \\
175(79 \%) \\
181(73 \%) \\
159(61 \%) \\
168(56 \%)\end{array}$} & \multirow{2}{*}{$\begin{array}{r}\begin{array}{c}\text { Locally } \\
\text { Advanced }\end{array} \\
19(18 \%) \\
30(14 \%) \\
50(20 \%) \\
71(27 \%) \\
106(35 \%)\end{array}$} & \multirow{2}{*}{$\begin{array}{r}\begin{array}{c}\text { Distant } \\
\text { Metastases }\end{array} \\
9(8 \%) \\
16(7 \%) \\
17(7 \% \%) \\
32(12 \%) \\
27(9 \%)\end{array}$} & \multirow{2}{*}{$\begin{array}{c}\begin{array}{c}\text { Total } \\
\text { Cases }\end{array} \\
109 \\
221 \\
248 \\
262 \\
301\end{array}$} \\
\hline $\begin{array}{r}<40 \\
40-49 \\
50-59 \\
60-69 \\
>70\end{array}$ & $\begin{array}{l}\cdots \\
\cdots \\
\cdots \\
\cdots\end{array}$ & $\begin{array}{l}\cdots \\
\cdots \\
\cdots \\
\cdots \\
\end{array}$ & $\begin{array}{l}\cdots \\
\cdots \\
\cdots \\
\cdots\end{array}$ & $\begin{array}{l}\cdots \\
\cdots \\
\cdots \\
\cdots\end{array}$ & & & & \\
\hline \multicolumn{3}{|c|}{ Total } & & & 764 & 276 & 101 & 1,141 \\
\hline
\end{tabular}

TABLE II.-Scar Recurrence in Relation to Age Group in 205 Women

\begin{tabular}{|c|c|c|c|c|c|c|c|c|c|}
\hline \multicolumn{8}{|c|}{ Age Group } & \multirow{2}{*}{\begin{tabular}{|c|} 
Cases \\
74 \\
57 \\
50 \\
24
\end{tabular}} & \multirow{2}{*}{$\begin{array}{c}\begin{array}{r}\text { Scar Recurrence } \\
\text { Within } 3 \text { Years }\end{array} \\
\begin{array}{r}20 \% \\
23 \% \\
22 \% \\
29 \%\end{array}\end{array}$} \\
\hline $\begin{array}{r}<50 \\
50-59 \\
60-69 \\
>70\end{array}$ & $\begin{array}{l}\cdots \\
\cdots \\
\cdots\end{array}$ & $\begin{array}{l}\cdots \\
\cdots \\
\cdots\end{array}$ & $\begin{array}{l}\ldots \\
\cdots \\
\cdots\end{array}$ & $\begin{array}{l}\quad . \\
\therefore \\
\therefore \\
.\end{array}$ & $\begin{array}{l}\ldots \\
\cdots \\
\cdots\end{array}$ & $\begin{array}{l}\cdots \\
\cdots \\
\cdots\end{array}$ & $\begin{array}{l}\ldots \\
\cdots \\
\cdots\end{array}$ & & \\
\hline
\end{tabular}

TABLE III.-Mean Interval Before Scar Recurrence in Relation to Age Group and Postoperative Irradiation of Scar Area

\begin{tabular}{|c|c|c|c|c|c|c|c|c|c|}
\hline & \multirow{2}{*}{\multicolumn{5}{|c|}{ Age Group }} & \multicolumn{4}{|c|}{ Mean Interval Before Scar Recurrence } \\
\hline & & & & & & \multicolumn{2}{|c|}{$\begin{array}{c}\begin{array}{c}\text { No Postoperative } \\
\text { Scar Radiotherapy }\end{array} \\
28 \text { months }\end{array}$} & \multicolumn{2}{|c|}{$\begin{array}{c}\text { Postoperative } \\
\text { Scar Radiotherapy }\end{array}$} \\
\hline $\begin{array}{r}<50 \\
50-59 \\
60-69 \\
>70 \\
\end{array}$ & $\begin{array}{l}\cdots \\
\cdots \\
\cdots \\
\cdots\end{array}$ & $\begin{array}{l}\cdots \\
\cdots \\
\cdots \\
\cdots\end{array}$ & $\begin{array}{l}\cdots \\
\because \\
\cdots \\
.\end{array}$ & $\begin{array}{l}\ldots \\
\cdots \\
\cdots \\
\cdots\end{array}$ & $\begin{array}{l}\cdots \\
\because \\
\cdots \\
\cdots\end{array}$ & $\begin{array}{l}28 \\
34 \\
24 \\
26 \\
\end{array}$ & $\begin{array}{l}\text { months } \\
\text { ", } \\
"\end{array}$ & $\begin{array}{l}16 \\
24 \\
22 \\
27\end{array}$ & $\begin{array}{l}\text { months } \\
\text { ", } \\
",\end{array}$ \\
\hline \multicolumn{2}{|c|}{ Mean } & & & & & 28 & & 21 & \\
\hline
\end{tabular}


Papadrianos et al. (1965) suggested that the degree of malignancy is decreased in breast cancer patients over the age of 65 , on the basis of a 13 months' longer average recurrence-free interval between mastectomy and the appearance of metastases. The latter include both local metastases (presumably in the skin or nodes) and distant metastases. Such evidence may not be valid, as there is considerable doubt about whether the rate of growth of metastases is equal to that of the primary tumour (Smithers, 1968).

As noted above, in our series the average interval between mastectomy and local scar recurrence does not appear to be lengthened in the older patient, though the slow-growing, clinically "atrophic scirrhous" primary breast tumour is relatively more common in elderly patients. Bloom (1950) noted that the histological distribution of low and high grades of malignancy in the primary tumours is the same for all age groups. It is therefore likely that the biological behaviour of a tumour is related only in part to the tumour histology, but depends also on the endocrine, metabolic, or immunological environment. While this might favour slow growth of the primary tumour in old age, recurrence or metastasis might involve tumours of specific biological type. It has been noted (Stoll, 1969) that response to hormone therapy is more likely with a longer recurrence-free interval, but that this characteristic cannot be linked with any specific histological picture.

\section{Results of Curative Treatment}

Adequate details of treatment were not available in 20 of the patients over 70 , leaving 281 to be analysed for the results of treatment. Of this total, $34.5 \%$ were treated primarily by mastectomy (radical or palliative), $23.5 \%$ by radiation therapy (radical or palliative), $29 \%$ by hormonal therapy, and $13 \%$ were left untreated (Table IV).

To assess the effect of curative treatment on survival the patients in stages 1 and 2 are considered (Table V). Of these, 88 were treated by surgery aiming at cure-radical or simple mastectomy (followed in 33 of the patients by radiation therapy). The healthier and younger patients in the group were obviously selected for these procedures, $87 \%$ of the patients being aged between 70 and 80 . In spite of this selection the five-year survival rate for 88 stage 1 and 2 cases treated by curative surgery (with or without postoperative radiotherapy) was $10 \%$. This figure is not significantly different from the five-year survival rate of $8 \%$ for locally advanced cases treated by radiation, "toilet" mastectomy, or hormone therapy.

These results can be interpreted either as a failure of treatment aiming at cure of breast cancer or that the possible benefits of such treatment have been swallowed up by a very

TABle IV.-Primary Treatment Method in 281 Women Aged Over 70

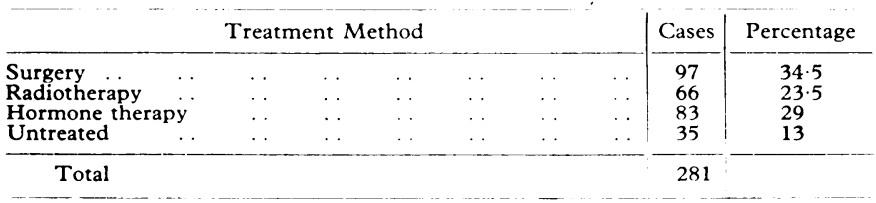

TABle V.-Patients Aged 70-95. Percentage Survival Year by Year According to Stage of Disease at Presentation and According to Method of Treatment

\begin{tabular}{|c|c|c|c|c|c|c|c|}
\hline \multirow{2}{*}{$\begin{array}{l}\text { Presenting } \\
\text { Stage }\end{array}$} & \multirow{2}{*}{$\begin{array}{c}\text { Primary } \\
\text { Treatment }\end{array}$} & \multirow{2}{*}{ Cases } & \multicolumn{5}{|c|}{ Years of Survival } \\
\hline & & & 1 & 2 & 3 & 4 & 5 \\
\hline 1 and $2 \ldots$ & Curative surgery & 88 & $83 \%$ & $53 \%$ & $34 \%$ & $19 \%$ & $10 \%$ \\
\hline 1 and 2 & $\begin{array}{l}\text { Hormones or radio- } \\
\text { therapy }\end{array}$ & 52 & $73 \%$ & $48 \%$ & $23 \%$ & $12 \%$ & $4 \%$ \\
\hline $\begin{array}{l}\text { Locally } \\
\text { advanced }\end{array}$ & $\begin{array}{l}\text { Hormones, simple } \\
\text { mastectomy, or } \\
\text { radiotherapy }\end{array}$ & 102 & $50 \%$ & $36 \%$ & $20^{\circ}$ & $13 \%$ & $8 \%$ \\
\hline \multicolumn{2}{|c|}{ Disseminated or untreated } & 39 & $20 \%$ & $15 \%$ & $5 \%$ & $3 \%$ & $3 \%$ \\
\hline \multicolumn{2}{|l|}{ Overall } & 281 & & & & & $7 \%$ \\
\hline
\end{tabular}

high proportion of deaths from intercurrent disease before the expiration of five years. The latter seems more likely, as shown by consideration of patients in stages 1 and 2 who were treated by radiotherapy or hormone therapy. These are a special group regarded as unfit for surgery because of poor general health, and they show a five-year survival rate of $4 \%$ - slightly lower than the operated group. When the year-byyear deaths are tabulated according to the treatment in stages 1 and 2 (Table V) the earlier deaths are more obvious in patients not treated by curative surgery, reflecting the selection of the less fit patients, but at five years the salvage rate is low in all groups.

Thus, in spite of the high five-year survival rate possible from radical surgery in selected series of older patients (Papadrianos et al., 1965), the survival rate is little affected in an unselected series when no allowance is made for patients dying of intercurrent disease before the expiration of five years. The conclusion is that the probability of a five-year survival in a woman over 70 with breast cancer will depend mainly on her general health.

\section{Results of Palliative Treatment}

Even if the expectation of life in a patient is less than five years because of advanced breast cancer or poor general health, it is important to reduce the suffering which would result from an offensive ulcerating tumour with associated haemorrhage, discharge, and pain.

Palliative simple mastectomy is practised for the removal of a mobile or ulcerated breast tumour even in the presence of metastases, so long as malignant tissue is not transected by the operation (Ackland et al., 1960). Radiotherapy is used for the control of localized manifestations of breast cancer, particularly if they are causing symptoms. Practically all types of soft-tissue deposits, including the primary tumour, skin nodules, and axillary and supraclavicular nodes, can be controlled by radiotherapy for periods of 6 to 24 months. Pain from bone metastases can be relieved and pressure symptoms from cerebral or mediastinal metastases can be controlled for six months or longer.

Even in the case of large tumours a two-day course of megavoltage therapy to the breast and draining node areas has been shown (Stoll, 1964) to achieve the same degree of palliation as the three- to five-week course generally in use. This short intensive course is no strain even on the oldest patient, is associated with a minimal skin reaction, and will control the local growth of the tumour for one to two years in late cases, but longer in stages 1 and 2. In most of these cases the patient dies of intercurrent disease or metastases before recurrence of the local disease presents a problem for management.

Oestrogen therapy (stilboestrol $15 \mathrm{mg}$. daily or ethinyloestradiol $1.5 \mathrm{mg}$. daily) was used to control tumour activity when surgery ar radiotherapy was unsuitable or incapable of controlling the disease. Side-effects, mainly severe nausea or fluid retention causing cardiac embarrassment, were sufficient to cause treatment to be discontinued in $11 \%$ of 170 patients in this age group. Of the 92 patients who could be assessed for response (Table VI) there was objective evidence of tumour regression in $49 \%$ of cases. In the responding cases the average survival after initiating therapy was 28 months, while in the non-responding cases it was only 16 months.

TABLE VI.-Response to Oestrogen Therapy by Breast Cancer in Women Aged $70-95$

\begin{tabular}{lllllll|l|l}
\multicolumn{3}{c}{ Oestrogen Therapy } & & & Cases & \\
\hline $\begin{array}{l}\text { Discontinued for toxicity } \\
\text { Inadequate trial }\end{array} \quad$. & $\ldots$ & $\ldots$ & $\ldots$ & $\ldots$ & $\ldots$ & 18 & $\begin{array}{c}\text { Excluded } \\
\text { Excluded }\end{array}$ \\
\hline $\begin{array}{l}\text { Regression of tumour } \\
\text { No regression of tumour }\end{array}$ & $\ldots$ & $\ldots$ & $\ldots$ & $\ldots$ & $\ldots$ & $\ldots$ & 45 & $49 \%$ \\
\hline \multicolumn{1}{c}{ Total } & & $\ldots$ & $\ldots$ & $\ldots$ & $\ldots$ & $\ldots$ & 47 & $51 \%$ \\
\hline
\end{tabular}


The highest response rate was in local soft-tissue tumour, particularly the primary tumour or metastatic nodules, while the response in metastatic nodes was less pronounced. Pulmonary and pleural metastases responded less often, and regression in bone or liver metastases was rarely seen from oestrogen therapy. Response to androgen therapy (fluoxymesterone $30 \mathrm{mg}$. daily) was, however, seen in $25 \%$ of cases with bone metastases.

\section{Discussion}

There is conflicting advice in the literature on the management of breast cancer in old age. Haagensen's group (Papadrianos et al., 1965) report that in their experience aged patients tolerate radical mastectomy well, and they therefore advise this procedure in all operable cases. They report $78.5 \%$ of five-year survivals and no postoperative deaths in 92 patients over 65, of whom almost half had metastatic involvement of axillary nodes. This salvage figure would be remarkable in any age group with breast cancer, even allowing that in their report patients dying of intercurrent disease in less than five years were omitted from assessment.

On the other hand, breast cancer in old age has certain characteristics which might militate against a decision to carry out radical surgery. Thus it has been suggested that since the average rate of tumour growth is lower in old age, the presence of the disease may not affect survival (Cade, 1948). It has also been noted that the local disease tends to be more advanced when the patient presents with it in old age (Kraft and Block, 1962; Philip, 1967). Finally, the frequent presence of cardiac disease in the patient over 70 will increase the operative mortality of radical surgery.

Bloom et al. (1962) noted a five-year survival of $12 \%$ in women over 70 with untreated breast cancer. In our series of 281 patients over 70, of whom $87 \%$ were treated, the overall five-year survival rate was $7 \%$. Shimkin (1951) noted a mean survival of 36 months in women over 75 with untreated breast cancer. In our total series the mean period of survival was 19 months. It would therefore appear that survival in our group of aged patients was not materially helped by treatment.

Bloom et al. (1962) concluded that treatment affects the likelihood of five-year survival most especially in the case of breast cancer with a high grade of malignancy. McDonald (1957), while agreeing that biological factors determine the natural history of breast cancer much more than the size of the tumour or the time and type of treatment, concluded that treatment could affect the prognosis in about $25 \%$ of cases. In the rest either remote metastases were already present when the patient was first seen or survival for five years would result from slow growth of the tumour, whatever the treatment given.

At present we have no means of determining the category of cure potential into which any individual patient will fall. For this reason we must assume that in the younger patient in stage 1 or 2 the prognosis will depend on the quality of treatment given, and this must be radical in intent. When, however, we are dealing with patients aged 70 to 95 this reasoning can apply only to the small minority who are in excellent physical condition and with a five-year expectation of life on general medical grounds. For the less fit patients, who comprise the majority, a palliative method or combination of treatments will control the tumour for three years or longer. When the patient is bedridden and has a short life expectancy no therapy at all is required.

Acknowledgements are made to the Director of the Cancer Institute, Melbourne, Australia, for kind permission to quote the material on which this study is based.

\section{REFERENCES}

Ackland, T. H., Holman, W. P., and Stoll, B. A. (1960). Medical Fournal of Australia, 1, 793.

Bloom, H. J. G. (1950). British fournal of Cancer, 4, 259, 347.

Bloom, H. J. G., Richardson, W. W., and Harries E. J. (1962). British Medical fournal, 2, 213.

Cade, S. (1948). Fournal of the American Medical Association, 138, 1083.

Kraft, R. O., and Block, G. E. (1962). Annals of Surgery, 156, 981.

McDonald, I. (1957). Proceedings of 3rd National Cancer Congress, p. 87 Philadelphia, Lippincott.

Papadrianos, E., Cooley, E., and Haagensen, C. D. (1965). Annals of Surgery, $161,189$.

Paterson, J. R. K. (1948). Treatment of Malignant Disease by Radium and $X$-Rays, p. 309. London, Arnold.

Philip, J. F. (1967). British Medical fournal, 1, 323.

Shimkin, M. B. (1951). Cancer (Philadelphia), 4, 1.

Smithers, D. W. (1968). Clinical Radiology, 19, 113.

Stoll, B. A. (1964). Clinical Radiology, 15, 175.

Stoll, B. A. (1969). Hormonal Management in Breast Cancer, p. 117. London, 